Portland State University

PDXScholar

\title{
What is the Impact of Economic Stimulus Measures on COVID-19 Mortality Rates?
}

Stephanie C. Santaguida

Portland State University

Follow this and additional works at: https://pdxscholar.library.pdx.edu/honorstheses

Part of the Behavioral Economics Commons, and the Health Economics Commons Let us know how access to this document benefits you.

\section{Recommended Citation}

Santaguida, Stephanie C., "What is the Impact of Economic Stimulus Measures on COVID-19 Mortality Rates?" (2021). University Honors Theses. Paper 967.

https://doi.org/10.15760/honors.991

This Thesis is brought to you for free and open access. It has been accepted for inclusion in University Honors Theses by an authorized administrator of PDXScholar. Please contact us if we can make this document more accessible: pdxscholar@pdx.edu. 


\title{
What is the Impact of Economic Stimulus Measures on COVID-19 Mortality Rates?
}

\author{
by \\ Stephanie C. Santaguida
}

An undergraduate honors thesis submitted in partial fulfillment of the requirements for the degree of

Bachelor of Science

in

University Honors

and

Economics

Thesis Advisor

J. Forrest Williams

Portland State University

2021 


\begin{abstract}
This inquiry seeks to establish the degree to which economic stimulus measures impact COVID-19 mortality rates. There appears to be an inverse correlation between domestic social spending and COVID-19 deaths. While confirmed infections are the most reliable predictor of mortality rates, trust in government is an important factor to consider when public compliance with health directives determines the degree of epidemiological risk in each country. Although most economists agree that stimulus monies directed to low-income individuals to prevent financial collapse were appropriate, there is some dissention with regard to the type and size of such cash infusions. Nonetheless, behavioral economists believe that any such payments ought to be large enough to incentivize compliance with lockdown and other containment measures. The COVID-19 pandemic is a historic event that will doubtless be analyzed from every angle; this inquiry seeks to contribute to that growing body of literature in hopes of guiding policymakers in achieving optimal outcomes through governmental spending measures in future emergencies.
\end{abstract}

\title{
JEL Classification Codes
}

C31, I18, I38, Z18

\section{Keywords}

COVID-19; Fiscal Stimulus Measures; Cultural Values; Ordinary Least Squares;

Public Policy

\section{Acknowledgements}

I would like to thank J. Forrest Williams for his inestimable assistance and support in the course of conducting this research, as well as the numerous peer reviewers and professors who provided encouragement, recommendations, and resources in this academic endeavor. 


\section{Table of Contents}

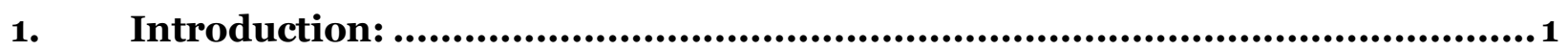

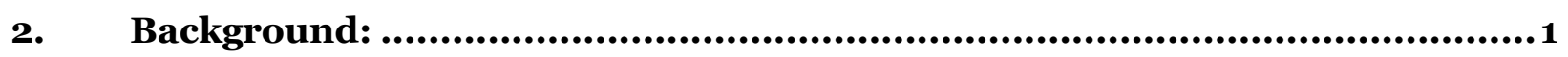

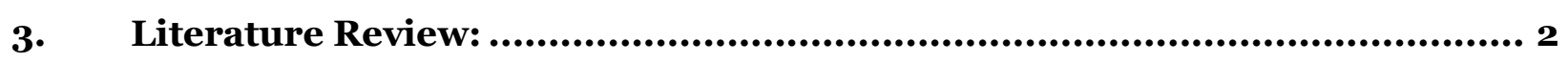

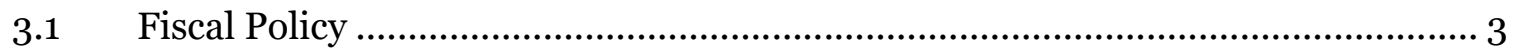

3.2 COVID-19 Containment Policies and Public Compliance ................................... 6

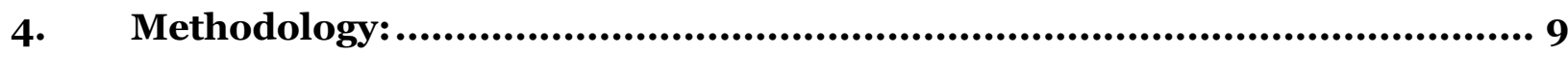

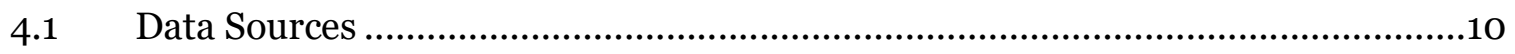

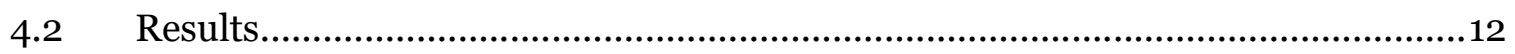

4.3 Robustness and Limitations ................................................................... 15

4.4 Further Research ................................................................................. 15

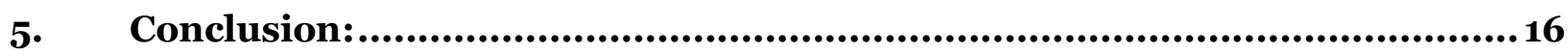

Appendix A - Boxplots ....................................................................................23

Appendix B - Regression Results and Assumption Tests ................................ 24 


\section{INTRODUCTION:}

This inquiry seeks to establish the degree to which economic stimulus measures impact COVID-19 death rates after controlling for cultural values such as in-group collectivism and trust in government, as well as each country's policies to contain the spread of the novel coronavirus, total COVID-19 infections per million population, and development in terms of quality of life and access to education and healthcare. I will begin by providing a background of the spread of COVID-19 and the rise in governmental measures to prevent infections, followed by a review of factors that improve and inhibit compliance with contagion-limiting practices, and the efficacy of governmental responses. Then I will describe the dependent and independent variables under consideration in this research, the econometric model utilized, and my results and conclusions. This inquiry seeks to contribute to a growing body of literature related to economic shocks and unanticipated disruptions to human activities which may guide policymakers in achieving optimal outcomes through governmental spending measures in future emergencies.

\section{BACKGROUND:}

COVID-19 is the illness that results from the novel coronavirus that emerged from the Wuhan region of China in late 2019 (Li et al., 2020; Rothan \& Byrareddy, 2020; Ciotti et al., 2020). COVID-19 presents with an array of symptoms and varying severity, but typical cases involve respiratory difficulties, neurological symptoms such as loss of taste or smell, digestive issues, body aches, and fever. Some cases are asymptomatic, while others become lifethreatening (p. 2, Rothan \& Byrareddy, 2020). The novel coronavirus is highly contagious, and rapidly spread from China to 20 other countries (South Korea, the United States, Macau, Singapore, Malaysia, Nepal, Vietnam, France, Australia, Canada, Cambodia, Sri Lanka, Germany, United Arab Emirates, Finland, India, the Philippines, Russia, Italy, and the United Kingdom) by the end of January 2020 (Kantis et al., 2020). 
On January 30, 2020, the World Health Organization declared the novel coronavirus a public health emergency at the second meeting of the International Health Regulations Emergency Committee. As COVID-19 infections surged to over 80,00o globally and the death toll surpassed 3,00o, governments around the world began issuing lockdown orders, travel bans, and a moratorium on large gatherings in February 2020. On March 11, 2020, the United Nations announced that one in five schoolchildren were no longer able to attend in-person classes due to the pandemic. By March 25, 2020, "[n]early one third of the world's population [was] affected by coronavirus lockdowns" (Kantis et al., 2020). The World Health Organization (2020) initially recommended that individuals wash their hands frequently, cover their mouth when they sneezed, and sanitize surfaces often (p. 3). In early April 2020, scientists confirmed that most person-to-person transmissions of the novel coronavirus occurred through airborne droplets, leading to the Centers for Disease Control and Prevention's recommendation that all members of the public wear fabric face masks when social distancing of at least 6 feet cannot be maintained or when in enclosed spaces with people who are not members of one's household (Fisher et al., 2020). In August 2020, the World Health Organization and International Monetary Fund reported that the pandemic cost the global economy over \$375 billion per month (Kantis et al., 2020). While the decision to stop international travel, ban large public gatherings, close schools, and enter lockdown varied in timing depending upon each country's infection rates, the economic consequences of the COVID-19 pandemic are undeniable and vast.

\section{LITERATURE REVIEW:}

Since the beginning of the COVID-19 pandemic, numerous academic treatises have been written with regard to the impact of contagion-limiting policy and their ensuing economic impacts. These inquiries can be categorized into analyses of fiscal policy and studies of containment policies to limit the spread of COVID-19 and public compliance thereunder. 


\subsection{Fiscal Policy}

The vast majority of economists endorse providing fiscal support for businesses and individuals during the COVID-19 pandemic (Agarwal et al., 2020; Alfaro et al., 2020; Ashraf, 2020a; Barrios et al., 2021; Brodeur et al., 2020; Carlsson-Szlezak et al., 2020a; CarlssonSzlezak et al., 2020b; Chang \& Velasco, 2020; Eichenbaum, Rebelo, \& Trabandt, 2020; Elgin, Basbug, \& Yalaman, 2020; Lou, Shen \& Niemeier, 2020; Rho, Brown \& Fremstad, 2020; Sieroń, 2020; Soofi, Najafi, \& Karami-Matin, 2020; Wright et al., 2020). As the pandemic forced business closures and a shift to virtual work in many industries, the risk of hunger and homelessness increased. Many governments responded to this sudden growth in economic instability by providing expanded unemployment benefits, direct cash stimulus to needy families, and subsidies to businesses to retain workers on their payrolls whilst unable to operate. The studies detailed below track the impact of COVID-19 containment measures on the economy, how to protect vulnerable populations from economic collapse, and how government policy responses may impact economic recovery once the COVID-19 pandemic is under control.

The impact of COVID-19 containment measures on the economy at large are quite significant. Brodeur et al. (2020) summarize Carlsson-Szlezak et al. (2020a) and CarlssonSzlezak et al.'s (2020b) research and state there are three ways that COVID-19 will impact the economy:

The first is the direct impact, which is related to the reduced consumption of goods and services. Prolonged lengths of the pandemic and the social distancing measures might reduce consumer confidence by keeping consumers at home, wary of discretionary spending and pessimistic about the long-term economic prospects. The second one is the indirect impact working through financial market shocks and their effects on the real economy. Household wealth will likely fall, savings will increase, and consumption spending will decrease further. The third consists of supply-side disruptions; as COVID-19 keeps production halted, 
it will negatively impact supply chains, labor demand, and employment, leading to prolonged periods of lay-offs and rising unemployment. (p. 18)

These impacts can be seen through firm layoffs, decreased consumer borrowing, reduced stock market returns, and shortages of goods. Makin \& Layton (2021) find that these changes in consumer and business behavior lead to a "sharp 2020 budget deficit spike" (p. 343) due to diminished income, sales, and value-added tax volume, in addition to increased social support spending. They question the wisdom of increased budget deficits and federal borrowing following the onset of the COVID-19 crisis, since governments will largely be accepting a debt burden for additional social welfare benefits without any tangible corresponding addition to government balance sheets. Further, Makin \& Layton (2021) state that granting cash support to low-income people during the pandemic is contrary to stay-at-home policies, and may be saved rather than spent due to economic uncertainty (p. 347). However, while a significant amount of economic activity shifted online as the pandemic grew in severity and lockdown measures were implemented, the prevailing perspective of economists is that means-tested cash bailouts to individuals and families are unlikely to loiter in low-income people's bank accounts when the degree of economic fallout from the COVID-19 crisis is so severe. Feeding America (Morello, 2021) states that $40 \%$ of the people served by food banks in the United States during the period March through October 2020 were receiving food assistance for the first time, and more than $80 \%$ of food banks encountered increased demand year-over-year. When food insecurity is at record levels in developed countries, cash infusions to underprivileged individuals appear not only to be the humane response, but also represent a relatively inexpensive alternative to outright economic collapse for the most vulnerable.

Fiscal stimulus packages allow governments to respond to the COVID-19 crisis and ameliorate some of the losses and instability that disadvantaged communities experience due to the pandemic. Lou, Shen \& Niemeier (2020) argue "[o]ne possible mitigation measure is prioritizing financial, health care and economic support for the vulnerable groups, especially for 
essential workers" (p. 17). These measures not only may stave off hunger and homelessness for low-income people, but also encourage compliance with COVID-19 public health recommendations. Chang \& Velasco (2020) determined that while all countries should seek to perform COVID-19 testing at as great a scale as possible, if policymakers intend to provide fiscal stimulus monies to induce workers to stay at home, the size of the stimulus measures should increase alongside the rate of testing since individuals will anticipate lower risks from returning to work if testing rates are higher (p. 17). Further, Soofi, Najafi, \& Karami-Matin (2020) argue that fiscal measures are an opportunity to improve the reward for compliance with public health directives, and have been shown to boost "adherence to antiretroviral medication, smoking cessation, and weight loss, and [...] to be effective in changing behaviors" (citations omitted) (p. 346). Thus, fiscal measures address not just the economic consequences of COVID-19, but also limit its spread and severity, leading to multiplicative policy benefits.

Financial markets also experienced volatility as a result of the COVID-19 pandemic. Ashraf (2020a) utilized daily stock market return data during the first several months of the COVID-19 pandemic to determine financial markets' responses to infection rates, lockdown orders, and economic stimulus packages. This study found that lockdown and social distancing orders had direct negative effects and indirect positive effects on stock market returns (due to reduced business activities and reduced infection rates respectively), but that income support packages led to improved financial market performance. Ashraf's conclusions lend credence to the underlying theory of this analysis that economic stimulus packages incentivize social distancing and contagion-limiting behavior, leading to lower infection rates among countries that implement robust income support packages.

Recovery from the COVID-19 crisis is dependent upon the population becoming immunized (either through vaccination or herd immunity), and a return to at least the previous level of economic activities. However, Carlsson-Szlezak, Reeves \& Swartz (2020b) find that while all previous pandemics caused V-shaped economic shocks, where there is a steep decline 
in output followed by a sharp recovery, the COVID-19 pandemic may not follow this trend due to the extraordinary lockdown measures imposed to control the spread of the virus. Makin \& Layton (2021) detail these vast economic effects as both an aggregate demand shock and aggregate supply shock due to supply chain breakdowns, closure of non-essential workplaces, loss of employment income to individuals and families, and increased uncertainty across the board (p. 340). As a result, more robust policy responses are recommended to address the extreme economic impact of COVID-19. "[Céspedes, Chang \& Velasco (2020)] argue the optimal policy response is to combine loosening of monetary policy with enhanced social insurance. In contrast, unconventional policies such as wage subsidies, helicopter drops of liquid assets, equity injections, and loan guarantees can keep the economy in a full employment, high-productivity equilibrium" (p. 44, Brodeur et al., 2020). Clearly, government fiscal policy is at risk of not being aggressive enough, rather than providing too much support and experiencing dead-weight loss.

\subsection{COVID-19 Containment Policies And Public Compliance}

While the financial impact of COVID-19 containment policies cannot be overstated, the impact and efficacy of containment policies are also a key object of study in the emerging body of academic literature. As El Zowalatya \& Järhultc (2020) succinctly state, "Coronaviruses represent a continuous pandemic threat; humans have experienced two coronavirus-related health security crises since 2003” (p. 1). As a result, government responses, albeit clearly deleterious economically, appear measured and necessary in the context of the highly transmissible and potentially fatal novel coronavirus. According to John Hopkins University (2020), containment measures consisting of social distancing, the closure of businesses, schools, churches and public gathering places are intended to "[flatten] the curve [by] reducing the number of new COVID-19 cases from one day to the next. This helps prevent healthcare systems from becoming overwhelmed." Especially at the beginning of the COVID-19 pandemic, medical experts acknowledged the impossibility of eliminating the disease without an effective vaccine, 
so limiting stress on healthcare systems became the primary object of concern. Unfortunately, some of these measures may have been more stringent than necessary. Agarwal et al. (2020), state that after a $40 \%$ decrease in mobility, "lifting severe mobility restrictions and only retaining moderate mobility restrictions (at retail and transit locations), seems to effectively flatten the curve" (emphasis in original) (p. 1). The diminishing effectiveness of decreasing human movements on limiting mortality rates may be a result of sufficiently flattening the curve to ensure hospital availability for COVID-19 infections that require intensive care. Nonetheless, some people may feel disheartened to recognize that a $40 \%$ decrease in mobility may have sufficient to optimally minimize COVID-19 deaths. El Zowalatya \& Järhultc (2020) emphasize that "a mixture of measures is important [to decrease human-to-human transmission] from strictly medical (transmission routes, efficiency of PPE, vaccines, antivirals and so on) to more social science-oriented (How do people behave when they suspect they could be infected? How do they behave when they are sick? How to potentially change these behaviours?)" (p. 6). While social distancing, travel bans and lockdown measures were appropriate from an epidemiological perspective, human behavior is not so simple or open to change regardless of public health recommendations.

A variety of factors appear to influence to what degree people comply with public health advisories to limit transmission of COVID-19. Wright et al. (2020) determined that poverty and economic dislocation related to or worsened by COVID-19 lockdown measures inhibit compliance with social distancing and shelter-in-place orders. Essential workers usually qualify as low income and/or perform services in environments that require interactions with scores of members of the public, such as pharmacies, grocery stores, healthcare, convenience stores, warehouses, public transit, and childcare (Rho, Brown \& Fremstad, 2020). Karaye \& Horney (2020) tested whether a social vulnerability index (compiled by the CDC and including measurements for socioeconomic status, household composition, disability, minority status, language spoken, and access to transportation) impacted COVID-19 infections per 100,000 
population, and found that the social vulnerability index overall, and all factors other than socioeconomic status, were statistically significant and positively correlated with increased COVID-19 infections (pp. 318-319). Meanwhile, Lou, Shen \& Niemeier (2020) determined that lower income individuals are "less likely to (be able) to follow the order to stay at home, controlling for other factors" (p. 16). As a result, it is reasonable to expect low-income individuals and their families to bear the brunt of the pandemic.

Barrios et al. (2021) utilize location data from cellular phones and data from surveys to conclusively determine that there is a link between regions with high levels of civic capital and voluntary compliance with social distancing measures, noting that "in the absence of any punishment, an infected individual derives no personal benefit from complying with public health recommendations, despite the potentially large social benefits" (p. 2). Similarly, Ashraf (2020b) reviewed 43 countries' uncertainty avoidance and COVID-19 confirmed infections in relation to stock market returns, theorizing that countries with higher uncertainty avoidance would panic-sell at higher rates in response to increased COVID-19 infections, even after taking significant losses in the stock market (pp. 3-4). The model confirmed this hypothesis and determined that cultural values are a significant factor in determining stock markets' responses to the COVID-19 pandemic. In accordance with Rousseau's (2016) famed stag hunt parable of game theory, individuals will only cooperate with one another for a higher payoff if they expect the other player to cooperate. If individuals are dubious of others' compliance with social distancing, hand washing, or mask-wearing protocols, they may determine that there is a higher return for non-compliance themselves and choose not to cooperate with the socially advantageous public health recommendations. Similarly, Brodeur et al. (2020) cite a study by Eichenbaum, Rebelo, \& Trabandt (2020) that emphasizes that "the competitive equilibrium is not Pareto optimal, as agents do not consider that their actions impact the infection and death rates of other economic agents. To properly internalize the externality, the authors suggest that the containment measures are optimal if they are tightened over time in proportion to the 
spread of infection" (p. 24). This, combined with Soofi, Najafi, \& Karami-Matin's (2020) finding that individuals believe they are less likely to catch the novel coronavirus than their peers, "even if their peers adhere to preventive practices" (p. 347), indicates that humans are poor judges of risky behaviors. As a result, people cannot be expected to comply with public health orders out of altruism or self-interest. In contrast, Alfaro, et al. (2020) found that "preference traits, such as patience, altruism, and trust, as well as community traits, such as reciprocity, matter for the behavioral response of individuals during a pandemic" (p. 41). Soofi, Najafi, \& Karami-Matin (2020) recommend framing health-protective behaviors in terms of gains to the individual, "such as 'If you wash your hands properly/follow social distancing policy/adhere to the stay-athome policy, you will increase the chances of yourself and your family having a long, healthy life" (p. 347), and "draw[ing] attention to what other people are doing" (p. 348). Through these simple changes in public service announcements, epidemiologists and healthcare professionals may utilize the wisdom of behavioral economics to maximize behavior change and minimize COVID-19 transmissions.

Given that individuals will only comply when they expect others to also comply with contagion-limiting protocols and otherwise default to status quo behavior, regions with higher civic capital (and thus higher rates of compliance) generate self-reinforcing effects that lead to fewer infections in certain regions. In order to account for these factors in this model, I will consider trust in government and in-group collectivism practices to control for regional differences in civic capital and its impacts on COVID-19 mortality rates.

\section{MethodologY:}

This research depends upon an ordinary least squares regression that measures a combined value of government domestic social spending and COVID-19 fiscal measures distributed to individuals and healthcare systems, COVID-19 infections per million population, a trust in government index, an in-group collectivism values index, a human development index, and a containment and health index's impact upon COVID-19 mortality rates. The regression is 
run traditionally and using the robust function to account for any heteroskedasticity with nearly identical results (see Table 1). The origins of the data and the transformations performed upon them are described in more detail below.

\subsection{Data Sources}

\subsubsection{FISCAL MEASURES AND COVID-19 INFECTION AND MORTALITY DATA}

The fiscal measures were determined utilizing data provided by the University of Oxford, Blatvatnik School of Government’s “Coronavirus Government Response Tracker” (Hale, et al., 2021) which included the total amount of fiscal measures provided to individuals and healthcare systems in 2020 U.S. dollars from the beginning of the pandemic through January 17, 2021. Using measurements of GDP per capita and current population for each country provided by Our World in Data, the emergency domestic fiscal measures provided to individuals and healthcare systems were calculated as a percentage of each country's GDP. This was combined with the OECD's social spending data as a percent of GDP as of 2017 in order to generate an approximation of each country's domestic social spending as a percent of GDP after the onset of the COVID-19 crisis. This aligns with OECD (2020) predictions that the "COVID-19 pandemic of 2020 is expected to lead to a marked increase in social spending” (p. 2). As a result, the combined value of 2017 domestic social spending, fiscal measures, and emergency healthcare funding as a percentage of GDP is intended to approximate the OECD's social spending indicator for 2020 until these figures become available. Meanwhile, COVID-19 infection and mortality rates are measured at a rate of per million population to account for variation in population size across the 27 countries evaluated. Next, I will discuss the various indexes utilized to control for variation in culture and government responsiveness in terms of lockdown and social distancing measures. 


\subsubsection{INDEXES FOR CULTURAL VALUES AND GOVERNMENT RESPONSE TO THE PANDEMIC}

In this research, a variety of indexes are used to control for cultural variation and asymmetrical responsiveness to the COVID-19 crisis, including the OECD's trust in government indicator, the Global Leadership and Organizational Behavior Effectiveness' 2004 Culture, Leadership, and Organizations study's in-group collectivism practices index, the United Nations Development Programme's human development index, and the University of Oxford's COVID-19 containment and health index. The OECD's trust in government indicator is on a scale of 1 to 100 and evaluates the share of survey respondents over a three-year period who responded “'yes' [...] to the survey question: 'In this country, do you have confidence in ... national government?”' (OECD). The GLOBE study includes indices for a number of cultural values and practices, including the in-group collectivism practices index which measures "the degree to which members in a culture express pride, loyalty, and interdependence in their families. [...] It is associated with pride in affiliation and a general affective commitment toward family, group, community, and nation” (Gupta \& Kirwan, 2013). Because the in-group collectivism practices index was determined on a seven-point scale while all other indexes in this research were on a scale of 1 to 100, the GLOBE scores for each country were divided by seven and multiplied by 100 to ensure uniformity in the model. In addition, the in-group collectivism practices index scores for East Germany and West Germany were combined proportional to the percent of population present in each region as of 2004 (Statistisches Bundesamt, 2017). The United Nations Development Programme's human development index provides a "summary measure of average achievement in key dimensions of human development: a long and healthy life, being knowledgeable and have a decent standard of living” (Roser et al., 2020). Finally, the University of Oxford's containment and health index aggregates 13 measures including school and workplace closures, the cancellation of public events, restrictions on gatherings, public transit closure, stay at home requirements, restrictions on internal movements, international travel controls, public information campaigns, testing policies, contact tracing, facial covering 
policies, and vaccination policies. Each of these closure, containment and health measures are determined on an ordinal scale from "no policy in place" to the most stringent policy possible. The index is then calculated by dividing each country's daily score for each measure listed above by the maximum ordinal value of that measurement, multiplied by 100 and averaged to generate a number between 1 and 100 (pp. 27-28, Hale et al., 2020).

\subsection{Results}

Table 1

\begin{tabular}{|lr|r|}
\hline \multirow{2}{*}{ Independent Variables } & \multicolumn{2}{c|}{ COVID-19 Deaths per Million Population } \\
& Traditional OLS & Robust OLS \\
\hline COVID-19 Infections per Million Population & 0.014 & 0.014 \\
& $(5.83)^{* *}$ & $(6.46)^{* *}$ \\
Trust in Government Index & 12.143 & -12.143 \\
& $(2.23) *$ & $(2.57)^{*}$ \\
Domestic Social Spending, Fiscal Measures and & -39.901 & -39.901 \\
Additional Healthcare Spending as a Percent of GDP & $(0.08)$ & $(0.09)$ \\
In-Group Collectivism Practices Index & -3.911 & -3.911 \\
& $(0.55)$ & $(0.72)$ \\
Human Development Index & -14.519 & -14.519 \\
& $(0.89)$ & $(1.01)$ \\
COVID-19 Containment and Health Index & -3.574 & -3.574 \\
& $(0.68)$ & $(0.75)$ \\
Constant & $2,542.737$ & $2,542.737$ \\
& $(1.47)$ & $(1.55)$ \\
$R^{2}$ & 0.733 & 0.733 \\
$N$ & 27 & 27 \\
\hline
\end{tabular}

${ }^{*} p<0.05 ;{ }^{* *} p<0.01$; parentheses indicate t-test values

Complete regression outputs are available in Appendix B.

Based upon this model, the baseline number of COVID-19 deaths is approximately 2,500 per million population, which increases with infections per million population, and decreases with the in-group collectivism practices index, the human development index, the containment and health index, and the sum of social spending, fiscal measures, and additional healthcare spending per million population. While Our World in Data (Roser et al., 2020) indicates a 
mean case fatality rate of about 2.1\% (COVID-19 infections per million resulting in COVID-19 deaths per million population) in the 23 countries included in this analysis, the model determines there is a $1.4 \%$ confirmed case fatality rate, demonstrating an overrepresentation of wealthy countries with advanced healthcare systems in this dataset or that some portion of the COVID-19 mortality rate is absorbed by the other explanatory variables in the model.

This model accounts for $73.3 \%$ of the variation in COVID-19 deaths per million population, although only the infections per million population and trust in government were statistically significant at a $1 \%$ and $5 \%$ level, respectively. While the majority of the independent variables in this model are not statistically significant, the relatively high $\mathrm{R}^{2}$ value and the intuitive signs of the coefficients indicate that the in-group collectivism practices index, the human development index, the containment and health index, and the combined value of domestic social spending, fiscal measures, and additional healthcare spending are correlated with fewer COVID-19 deaths, even if the null hypothesis that these variables have no impact on COVID-19 cannot be empirically rejected.

It is unsurprising that fiscal measures intended to restore economic activity and rescue impoverished families during the COVID-19 pandemic were not a statistically significant predictor of COVID-19 deaths. While fewer deaths are correlated with more domestic social spending and fiscal measures, Brodeur et al. (2020) reviewed a study from Elgin, Basbug \& Yalaman (2020) which found that a COVID-19 “'Stringency Index' [was] a not a significant predictor of economic stimulus, which suggests that public health measures do not drive economic stimulus measures" (p. 38). A stronger correlation may have been evident if governments responded to increased infections and deaths with higher fiscal allotments, but such a response may not have been economically advisable. While it is important for policymakers to ensure that fiscal stimulus measures are sufficient to encourage contagionlimiting behavior (id., p. 43), stimulus measures were primarily directed toward rescuing lowincome families from economic collapse and financial ruin. In fact, stimulus measures were 
primarily distributed in hopes of dispelling the risks of a domestic and global financial crisis, especially with the specter of the Great Recession so recent in many economists' and policymakers' memories. As observed in 2008, an economic crisis may have global impacts on financial markets due to the interconnected nature of the modern global economy (Helleiner, 2011).

Perhaps more unexpected is the meager impact of containment and health restrictions on COVID-19 mortality rates. The containment and health restrictions measured by the University of Oxford's “Coronavirus Government Response Tracker” (Hale, et al., 2021) may be negatively correlated at a statistically insignificant level due to a time lag in some countries adopting restrictions on commerce, travel, and non-essential social interactions, or due to the inherent flaws in measuring government policy on an ordinal scale to generate an index for the restrictiveness of various countries' response to the pandemic. If the issue lies in the former possibility, a time series dataset may have different results from those found herein. The final alternative is that as our knowledge and understanding of how COVID-19 spreads from personto-person improves, containment and health policy responses may become more effectual and accurate in targeting high-risk activities. As it stands, the "closest analogy [to the current contagion-limiting approach] is to government command and control of economies in wartime, in this case with the virus as the foreign invader" (p. 340, Makin \& Layton, 2021). Some measures to control spread of the virus have been criticized as draconian, and while the costs of lockdown measures are certainly quite high (as high as "\$7 trillion per year of shutdown" in the United States alone [p. 2, Mulligan, 2020]), Sieron (2020) explains that "COVID-19 is an infectious disease, which means that the risk is multiplicative. It implies that actions that seem irrational or exaggerated at an individual level are precisely the actions we need from the systemic point of view" (p. 5). Nonetheless, it is disheartening to question whether the impact of these containment measures was as substantial as policymakers hoped. 
Finally, while primarily included in this model in order to control for anticipated variation across OECD countries, the negative correlation between COVID-19 deaths and ingroup collectivism practices, trust in government, and the human development index align with expectations that greater pride in country, confidence in government communiques, and access to quality healthcare would improve COVID-19 infection rates and mortality rates.

\subsection{ROBUSTNESS AND LIMITATIONS}

The ordinary least squares regressions in this analysis meet the seven assumptions of econometric regression modeling as demonstrated by the graphs and summary statistics in Appendix B. The relationships are more or less linear based upon the kernel-weighted local polynomial regression performed upon each of the independent variables. The variance inflation factor scores indicate multicollinearity is not an issue in these models. The mean of the error terms is very nearly zero (-0.00000126). The independent variables are not correlated with residuals and there is no pattern to the distribution that would indicate heteroskedasticity (see Residuals vs. Fitted Values graph on page 26). There is no serial correlation in the models since the data are cross-sectional. No independent variable is perfectly correlated with any other variable (see Correlation Matrix on page 26). Finally, the error term is normally distributed (see Density vs. Residuals graph on page 25). As a result, while the model is largely not statistically significant, ordinary least squares regressions appear to be appropriate in the context of this analysis.

\subsection{FURTHER RESEARCH}

Because the models utilized herein were not as conclusive as hoped, there are a number of directions that future research may take in order to more effectively determine the relationship between COVID-19 fiscal measures and mortality rates. Time series data for a larger grouping of countries may be useful to more accurately reflect containment measures and fiscal stimulus measures' impact on mortality rates, given that there is a time delay between 
cash infusions and alteration of consumer activity (p. 41, Pindyck \& Rubinfeld, 2009) and that some countries enacted containment measures more rapidly in response to confirmed infections than others. Further, a difference-in-differences approach may be useful to contrast excess deaths and COVID-19 fiscal stimulus measures with pre-pandemic norms. Additionally, generating a categorical variable that divides each countries' residents into low-income, middleincome, and high-income tiers and reflects the infection and mortality rates for each group may allow the impact of fiscal measures (which primarily were distributed to low-income individuals) to be more apparent. Finally, once the OECD's social spending indicator for 2020 is available, it may be worthwhile to repeat the regressions herein in order to determine the degree of accuracy achieved by combining emergency COVID-19 healthcare spending, stimulus measures to individuals, and the 2017 social spending indicator to determine domestic welfare budgeting during the COVID-19 crisis.

\section{Conclusion:}

This inquiry sought to establish the degree to which economic stimulus measures impact COVID-19 mortality rates. While the results herein are not as conclusive as hoped, there does appear to be an inverse correlation between domestic social spending and COVID-19 deaths. Further, while confirmed infections are the most reliable predictor of mortality rates, trust in government is an important factor to consider when public compliance with health directives determines the degree of epidemiological risk in each country. Although most economists agree that stimulus monies directed to low-income individuals to prevent financial collapse were appropriate, there is some dissention with regard to the type and size of such cash infusions. Nonetheless, behavioral economists believe that any such payments ought to be large enough to incentivize compliance with lockdown and other containment measures. The COVID-19 pandemic is a historic event that will doubtless be analyzed from every angle; this inquiry seeks to contribute to that growing body of literature in hopes of guiding policymakers in achieving optimal outcomes through governmental spending measures in future emergencies. 


\section{References}

Agarwal, A., Alomar, A., Sarker, A., Shah, D., Shen, D., \& Yang, C. (2020). Two Burning Questions on COVID-19: Did Shutting Down the Economy Help? Can We (Partially) Reopen the Economy without Risking the Second Wave?. Retrieved February 26, 2021, from https://arxiv.org/abs/2005.00072.

Al-Arah, R. (2020). Hunger is Rising, COVID-19 Will Make it Worse. Global Humanitarian Overview 2021. Retrieved February 24, 2021, from https://gho.unocha.org/globaltrends/hunger-rising-covid-19-will-make-it-worse.

Alfaro, L., Faia, E., Lamersdorf, N., \& Saidi, F. (2020). Social Interactions in Pandemics: Fear, Altruism, and Reciprocity (Working Paper). National Bureau of Economic Research. https://doi.org/10.3386/w27134.

Ashraf, B. N. (2020a). Economic Impact of Government Interventions during the COVID-19 Pandemic: International Evidence from Financial Markets. Journal of Behavioral and Experimental Finance, 27. doi: 10.1016/j.jbef.2020.100371.

Ashraf, B. N. (2020b). Stock Markets' Reaction to COVID-19: Moderating Role of National Culture. Finance Research Letters, 1-9. doi: 10.1016/j.frl.2020.101857.

Barrios, J. M., Benmelech, E., Hochberg, Y. V., Sapienza, P., \& Zingales, L. (2021). Civic Capital and Social Distancing during the Covid-19 Pandemic. Journal of Public Economics, 193, 104310. doi: 10.1016/j.jpubeco.2020.104310.

Brewer, P., \& Venaik, S. (2011). Individualism-Collectivism in Hofstede and GLOBE. Journal of International Business Studies, 42(3), 436-445. doi: 10.1057/jibs.2010.62.

Brodeur, A., Gray, D., Islam, A., \& Bhuiyan, S. (2020). A Literature Review of the Economics of COVID-19 (Working Paper). I Z A Institute of Labor Economics, 1-61. Retrieved February 9, 2021, from https://www.iza.org/publications/dp/13411/a-literature-reviewof-the-economics-of-covid-19. 
Carlsson-Szlezak, Philipp, Reeves, M., \& Swartz, P. (2020a). Understanding the Economic Shock of Coronavirus. Harvard Business Review. Retrieved February 9, 2021, from https://hbr.org/2020/03/understanding-the-economic-shock-of-coronavirus.

Carlsson-Szlezak, Phillip, Reeves, M., \& Swartz, P. (2020b). What Coronavirus Could Mean for the Global Economy. Harvard Business Review. Retrieved February 9, 2021, from https://hbr.org/2020/03/what-coronavirus-could-mean-for-the-global-economy.

Céspedes, L. F., Chang, R., \& Velasco, A. (2020). The Macroeconomics of a Pandemic: A Minimalist Model (Working Paper). National Bureau of Economic Research. https://doi.org/10.3386/w27228.

Chang, R., \& Velasco, A. (2020). Economic Policy Incentives to Preserve Lives and Livelihoods (Working Paper). National Bureau of Economic Research, 1-23. doi: 10.3386/w27020. Ciotti, M., Angeletti, S., Minieri, M., Giovannetti, M., Benvenuto, D., Pascarella, S., ... Ciccozzi, M. (2020). COVID-19 Outbreak: An Overview. Chemotherapy, 64, 215-223. doi: $10.1159 / 000507423$.

Eichenbaum, M., Rebelo, S., \& Trabandt, M. (2020). The Macroeconomics of Epidemics (Working Paper). National Bureau of Economic Research, 1-48. doi: 10.3386/w26882. El Zowalaty, M. E., \& Järhult, J. D. (2020). From SARS to COVID-19: A Previously Unknown SARS-Related Coronavirus (SARS-CoV-2) of Pandemic Potential Infecting Humans Call for a One Health Approach. One Health (Amsterdam, Netherlands), 9(100124), 1-6. doi: 10.1016/j.onehlt.2020.100124.

Elgin, C. \& Basbug, G. \& Yalaman, A. (2020). Economic Policy Responses to a Pandemic: Developing the COVID-19 Economic Stimulus Index. The Centre for Economic Policy Research, 3, 40-53. Retrieved February 25, 2021, from https://www.researchgate.net/publication/343850621 Economic Policy Responses t o a Pandemic Developing the COVID-19 Economic Stimulus Index. 
Farzanegan, M. R., Feizi, M., \& Gholipour, H. F. (2020). Globalization and Outbreak of COVID19: An Empirical Analysis (Working Paper). Leibniz Institute for Economic Research at the University of Munich, 8315, 1-21. Retrieved February 15, 2021, from https://www.econstor.eu/bitstream/10419/219133/1/cesifo1 wp8315.pdf.

Feinhandler, I., Cilento, B., Beauvais, B., Harrop, J., \& Fulton, L. (2020). Predictors of Death Rate during the COVID-19 Pandemic. Healthcare, 8(3), 339, 1-16. doi: 10.3390/healthcare8030339.

Fisher, K. A., Barile, J. P., Guerin, R. J., Vanden Esschert, K. L., Jeffers, A., Tian, L. H., . . Prue, C. E. (2020). Factors Associated with Cloth Face Covering Use Among Adults During the COVID-19 Pandemic. Morbidity and Mortality Weekly Report, 69(28), 933-937. doi: 10.15585/mmwr.mm6928e3.

Global Leadership and Organizational Behavior Effectiveness (2004). An Overview of the 2004 Study: Understanding the Relationship Between National Culture, Societal Effectiveness and Desirable Leadership Attributes. Retrieved January 6, 2021, from https://globeproject.com/study 2004 2007?page id=data\#data.

Gupta, V., \& Kirwan, P. (2013). Role of In-Group Collectivism in the Longevity of Family Firms. Global Business Perspectives, 1, 433-451. https://doi.org/10.1007/s40196-013-0022-7.

Hale, T. et al. Coronavirus Government Response Tracker. University of Oxford, Blavatnik School of Government. Retrieved January 17, 2021, from https://www.bsg.ox.ac.uk/research/research-projects/coronavirus-governmentresponse-tracker.

Helleiner, E. (2011). Understanding the 2007-2008 Global Financial Crisis: Lessons for Scholars of International Political Economy. Annual Review of Political Science, 14(1), 67-87. doi: 10.1146/annurev-polisci-050409-112539.

John Hopkins University (2020). New Cases of COVID-19 In World Countries. Retrieved February 18, 2021, from https://coronavirus.jhu.edu/data/new-cases. 
Kantis, C., Kiernan, S., \& Bardi, J. S. (2021). UPDATED: Timeline of the Coronavirus. Think Global Health. Retrieved January 18, 2021, from https://www.thinkglobalhealth.org/article/updated-timeline-coronavirus.

Karaye, I. M., \& Horney, J. A. (2020). The Impact of Social Vulnerability on COVID-19 in the U.S.: An Analysis of Spatially Varying Relationships. American Journal of Preventive Medicine, 59(3), 317-325. doi: 10.1016/j.amepre.2020.06.006.

Li, Q., Guan, X., Wu, P., Wang, X., Zhou, L., Tong, Y., . . Feng, Z. (2020). Early Transmission Dynamics in Wuhan, China, of Novel Coronavirus-Infected Pneumonia. New England Journal of Medicine, 382(13), 1199-1207. doi: 10.1056/nejmoa2001316.

Lou, J. and Shen, X. and Niemeier, D. (2020). Are Stay-At-Home Orders More Difficult to Follow for Low-Income Groups? Journal of Transport Geography, 89(102894), 1-24. doi: 10.1016/j.jtrangeo.2020.102894.

Makin, A. J., \& Layton, A. (2021). The Global Fiscal Response to COVID-19: Risks and Repercussions. Economic Analysis and Policy, 69, 340-349. doi: 10.1016/j.eap.2020.12.016.

Morello, P. (2020). The Food Bank Response to COVID, By the Numbers. Feeding America. Retrieved February 24, 2021, from https://www.feedingamerica.org/hunger-blog/foodbank-response-covid-numbers.

Mulligan, C. B. (2020). Economic Activity and the Value of Medical Innovation during a Pandemic (Working Paper). National Bureau of Economic Research. https://doi.org/10.3386/w27060.

OECD (2020). Social Expenditure (SOCX) Update 2020: Social Spending Makes Up 20\% of OECD GDP. Retrieved February 19, 2021, from http://www.oecd.org/social/expenditure.htm.

OECD (2021). Social Spending (indicator). doi: 10.1787/7497563b-en.

OECD (2021). Trust in Government (indicator). doi: 10.1787/1de9675e-en. 
Pindyck, R. S., \& Rubinfeld, D. L. (2009). Microeconomics (7th ed.). Upper Saddle River, NJ: Pearson Press.

Rho, H., Brown, H., \& Fremstad, S. (2020). A Basic Demographic Profile of Workers in Frontline Industries. Retrieved February 14, 2021, from https://cepr.net/a-basicdemographic-profile-of-workers-in-frontline-industries/.

Roser, M., Ritchie, H., Ortiz-Ospina, E., \& Hasell, J. (2020). Coronavirus Pandemic (COVID-19) - Statistics and Research, Our World in Data. Retrieved January 6, 2021, from https://ourworldindata.org/coronavirus.

Rothan, H. A., \& Byrareddy, S. N. (2020). The Epidemiology and Pathogenesis of Coronavirus Disease (COVID-19) Outbreak. Journal of Autoimmunity, 109(102433). doi: 10.1016/j.jaut.2020.102433.

Rousseau, J. (2016). A Discourse on Inequality. New York: Philosophical Library/Open Road. Sieroń, A. (2020). Does the COVID-19 Pandemic Refute Probability Neglect? Journal of Risk Research, 23(7-8), 855-861. doi: 10.1080/13669877.2020.1772346.

Soofi, M., Najafi, F., \& Karami-Matin, B. (2020). Using Insights from Behavioral Economics to Mitigate the Spread of COVID-19. Applied Health Economics and Health Policy, 18(3), 345-350. doi: 10.1007/s40258-020-00595-4.

Statistisches Bundesamt. (2017). Population in the Former Territories of the Federal Republic of Germany and the German Democratic Republic from 1950 to 2016. Retrieved January 6, 2021, from https://www-statista-com.proxy.lib.pdx.edu/statistics/1054199/populationof-east-and-west-germany/.

Stokes, A., Lundberg, D. J., Hempstead, K., Elo, I. T., \& Preston, S. H. (2020). Assessing the Impact of the COVID-19 Pandemic on US Mortality: A County-Level Analysis (Working Paper). 1-25. doi: 10.1101/2020.08.31.20184036. 
World Health Organization (2020). Considerations for Quarantine of Individuals in the Context of Containment for Coronavirus Disease (COVID-19): Interim Guidance. Retrieved February 26, 2021, from https://apps.who.int/iris/handle/10665/331497.

Worldometer (2021). COVID-19 Coronavirus Pandemic. Retrieved January 18, 2021, from https://www.worldometers.info/coronavirus/.

Wright, A. L., Sonin, K., Driscoll, J., \& Wilson, J. (2020). Poverty and Economic Dislocation Reduce Compliance with COVID-19 Shelter-in-Place Protocols. Journal of Economic Behavior \& Organization, 180, 544-554. doi: 10.1016/j.jebo.2020.10.008. 


\section{APPENDIX A - BOXPLOTS}
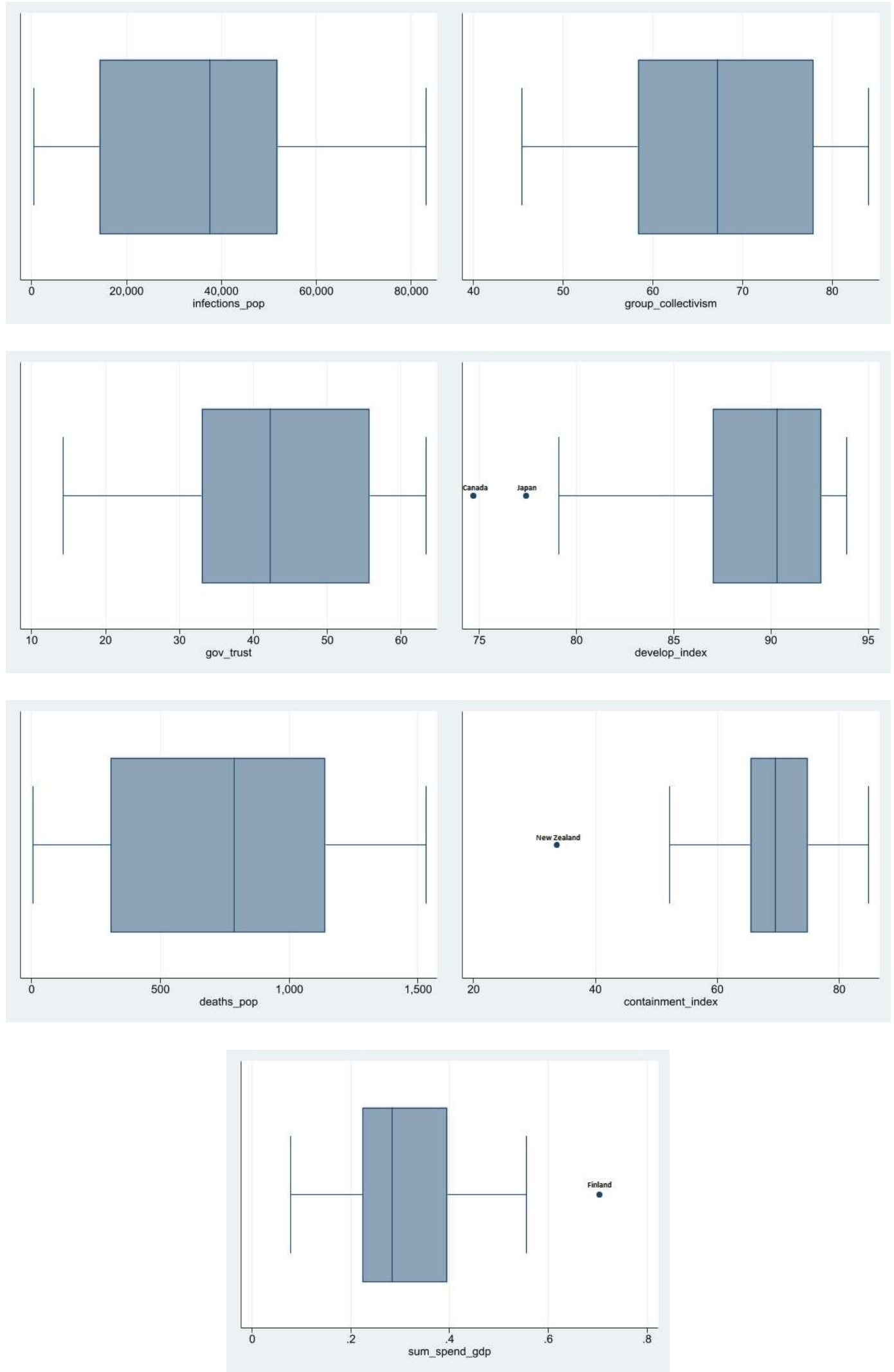


\title{
APPENDIX B - REGRESSION RESULTS AND ASSUMPTION TESTS
}

\author{
$\underline{\text { Robust Ordinary Least Squares Regression }}$
}

\begin{tabular}{|c|c|c|c|c|c|c|}
\hline Linear regression & & & \multicolumn{2}{|c|}{$\begin{array}{l}\text { Number of obs } \\
F(6,20) \\
\text { Prob > F } \\
\text { R-squared } \\
\text { Root MSE }\end{array}$} & \multicolumn{2}{|c|}{$\begin{array}{r}27 \\
16.91 \\
0.0000 \\
0.7327 \\
277.49\end{array}$} \\
\hline deaths_pop & Coef. & $\begin{array}{l}\text { Robust } \\
\text { Std. Err. }\end{array}$ & $\mathrm{t}$ & $P>|t|$ & [95\% Conf. & Interval] \\
\hline sum_spend_gdp & -39.9012 & 461.9238 & -0.09 & 0.932 & -1003.457 & 923.655 \\
\hline infections_pop & .0144774 & .0022412 & 6.46 & 0.000 & .0098023 & .0191525 \\
\hline gov_trust & -12.14279 & 4.721701 & -2.57 & 0.018 & -21.99209 & -2.293494 \\
\hline group_collectivism & -3.910786 & 5.430543 & -0.72 & 0.480 & -15.2387 & 7.417129 \\
\hline develop_index & -14.51854 & 14.31892 & -1.01 & 0.323 & -44.38728 & 15.3502 \\
\hline containment_index & -3.573665 & 4.750175 & -0.75 & 0.461 & -13.48236 & 6.335027 \\
\hline _cons & 2542.737 & 1644.576 & 1.55 & 0.138 & -887.7886 & 5973.262 \\
\hline
\end{tabular}

. vif

\begin{tabular}{r|rr} 
Variable & VIF & $1 /$ VIF \\
\hline develop_in x & 2.32 & 0.431129 \\
group_coll m & 2.19 & 0.457604 \\
gov_trust & 1.89 & 0.528070 \\
sum_spend dp & 1.49 & 0.672855 \\
infections p & 1.13 & 0.886803 \\
containmen x & 1.06 & 0.943413 \\
\hline Mean VIF & 1.68 &
\end{tabular}




\section{Traditional Ordinary Least Squares Regression}

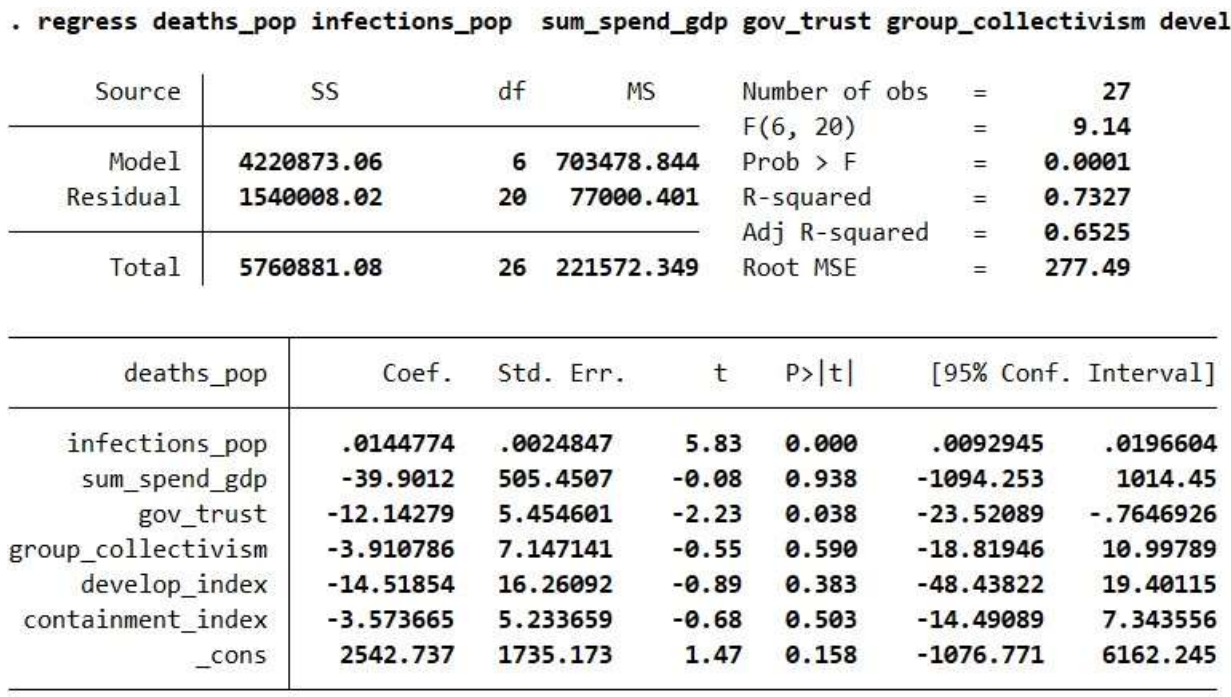

. vif

\begin{tabular}{r|rr} 
Variable & VIF & $1 /$ VIF \\
\hline develop_in x & 2.32 & $\mathbf{0 . 4 3 1 1 2 9}$ \\
group_coll m & 2.19 & $\mathbf{0 . 4 5 7 6 0 4}$ \\
gov_trust & 1.89 & $\mathbf{0 . 5 2 8 0 7 0}$ \\
sum_spend dp & 1.49 & $\mathbf{0 . 6 7 2 8 5 5}$ \\
infections p & 1.13 & $\mathbf{0 . 8 8 6 8 0 3}$ \\
containmen x & 1.06 & $\mathbf{0 . 9 4 3 4 1 3}$ \\
\hline Mean VIF & 1.68 &
\end{tabular}

\section{Density vs. Residuals}

Errors are Normally Distributed

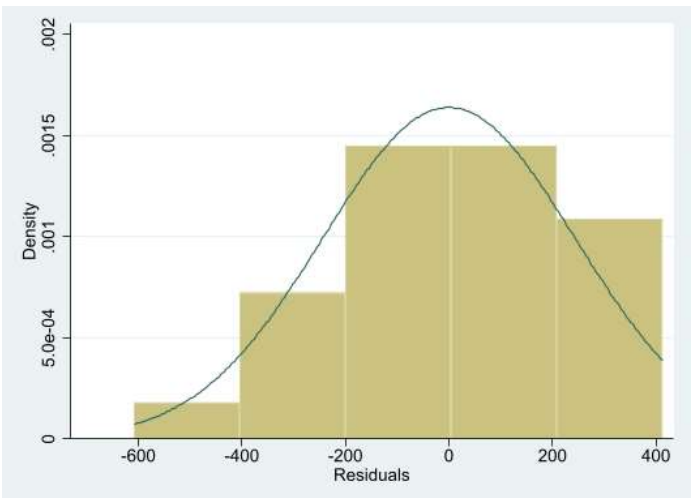




\section{Correlation Matrix}

(Residuals Not Correlated with Independent Variables)

- corr residuals infections_pop sum_spend_gdp gov_trust group_collectivism develop_index containment_index (obs=27)

\begin{tabular}{r|rrrrrrr} 
& residu s & infect p sum_s dp gov_tr t group_ m develo x contai x \\
\hline residuals & 1.0000 & & & & & & \\
infections p & 0.0000 & 1.0000 & & & & & \\
sum_spend dp & 0.0000 & 0.0558 & 1.0000 & & & & \\
gov_trust & -0.0000 & -0.1570 & -0.2436 & 1.0000 & & & \\
group_coll m & -0.0000 & -0.1251 & -0.2101 & -0.4852 & 1.0000 & & \\
develop_in x & -0.0000 & 0.0215 & 0.3393 & 0.4511 & -0.6886 & 1.0000 & \\
containmen x & 0.0000 & 0.2105 & -0.0155 & -0.1146 & -0.0104 & -0.0261 & 1.0000
\end{tabular}

$\underline{\text { Residuals vs. Fitted Values Graph }}$

(Residuals Not Correlated with Fitted Values)

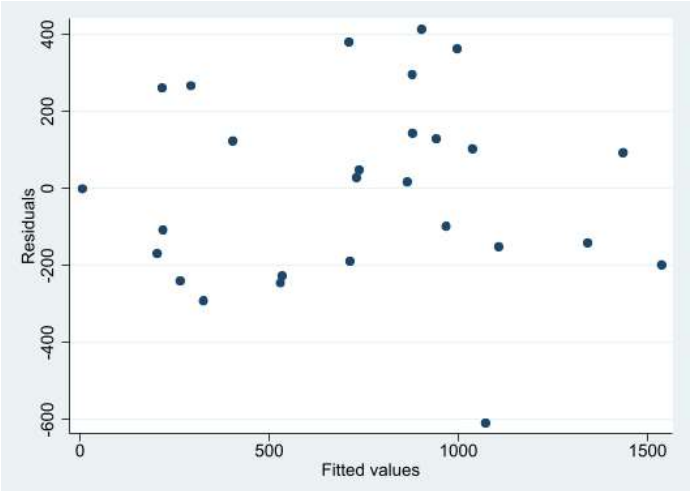

